\title{
Glutamine-enriched enteral nutrition in very low birth weight infants. Design of a double-blind randomised controlled trial [ISRCTN73254583]
}

\author{
Anemone van den Berg*1, Ruurd M van Elburg1, Jos WR Twisk ${ }^{2}$ and \\ Willem PF Fetter ${ }^{1}$
}

Address: ${ }^{1}$ Department of Paediatrics, Division of Neonatology, VU University Medical Center, Amsterdam, the Netherlands and ${ }^{2}$ Institute of Research in Extramural Medicine, VU University Medical Center, Amsterdam, the Netherlands

Email: Anemone van den Berg* - a.vandenberg@vumc.nl; Ruurd M van Elburg - rm.vanelburg@vumc.nl; Jos WR Twisk - jwr.twisk@vumc.nl; Willem PF Fetter - w.fetter@vumc.nl

* Corresponding author

Published: 0 I September 2004

BMC Pediatrics 2004, 4:17 doi:10.1186/147I-2431-4-17
Received: 12 August 2004

Accepted: 0 I September 2004

This article is available from: http://www.biomedcentral.com/I47I-243I/4/I7

(C) 2004 van den Berg et al; licensee BioMed Central Ltd.

This is an open-access article distributed under the terms of the Creative Commons Attribution License (http://creativecommons.org/licenses/by/2.0), which permits unrestricted use, distribution, and reproduction in any medium, provided the original work is properly cited.

\begin{abstract}
Background: Enteral feeding of very low birth weight (VLBW) infants is a challenge, since metabolic demands are high and administration of enteral nutrition is limited by immaturity of the gastrointestinal tract. The amino acid glutamine plays an important role in maintaining functional integrity of the gut. In addition, glutamine is utilised at a high rate by cells of the immune system. In critically ill patients, glutamine is considered a conditionally essential amino acid. VLBW infants may be especially susceptible to glutamine depletion as nutritional supply of glutamine is limited in the first weeks after birth. Glutamine depletion has negative effects on functional integrity of the gut and leads to immunosuppression. This double-blind randomised controlled trial is designed to investigate the effect of glutamine-enriched enteral nutrition on feeding tolerance, infectious morbidity and short-term outcome in VLBW infants. Furthermore, an attempt is made to elucidate the role of glutamine in postnatal adaptation of the gut and modulation of the immune response.

Methods: VLBW infants (gestational age $<32$ weeks and/or birth weight $<1500 \mathrm{~g}$ ) are randomly allocated to receive enteral glutamine supplementation $(0.3 \mathrm{~g} / \mathrm{kg} /$ day $)$ or isonitrogenous placebo supplementation between day 3 and 30 of life. Primary outcome is time to full enteral feeding (defined as a feeding volume $\geq 120 \mathrm{~mL} / \mathrm{kg} / \mathrm{day}$ ). Furthermore, incidence of serious infections and short-term outcome are evaluated. The effect of glutamine on postnatal adaptation of the gut is investigated by measuring intestinal permeability and determining faecal microflora. The role of glutamine in modulation of the immune response is investigated by determining plasma Thl/Th2 cytokine concentrations following in vitro whole blood stimulation.
\end{abstract}

\section{Background}

Enteral feeding of very low birth weight (VLBW) infants is a challenge, since metabolic demands are high and administration of enteral nutrition is limited by immatu- rity of the gastrointestinal tract. In particular, small for gestational age VLBW infants may have impaired gut function, as fetal blood flow to heart, brain and adrenals is compensatory increased, while other organs including the 
gastro-intestinal tract are relatively hypoperfused in intrauterine growth retardation [1].

Experimental studies have shown that the amino acid glutamine plays an important role in maintaining functional integrity of the gut [2-5]. Glutamine serves as fuel for enterocytes [2] and provides nitrogen for the synthesis of amino sugars, involved in maintenance of tight junctions [3] and mucin synthesis [4]. Moreover, glutamine has a stimulatory and regulatory effect on mucosal cell proliferation and differentiation [5].

Glutamine is not only utilised at a high rate by intestinal epithelium but also by cells of the immune system. In vitro studies have shown that increasing availability of glutamine stimulates proliferation of T-lymphocytes in response to T-cell mitogens [6], phagocytosis and antigen presentation by monocytes [7] and Th1 cytokine response [8].

In critically ill patients, endogenous glutamine synthesis cannot meet increased demand and for this reason glutamine is considered a conditionally essential amino acid [9]. VLBW infants may be especially susceptible to glutamine depletion as placental supply suddenly ceases at birth, tolerance of enteral nutrition is limited and parenteral nutrition does not contain glutamine for solubility and stability reasons. Glutamine depletion has negative effects on the functional integrity of the gut [10] and leads to immunosuppression [11].

Studies in adults have shown that glutamine supplementation decreases mortality in critically ill adults [12], infectious morbidity in recipients of bone marrow transplantation [13] and multiple trauma patients [14] and length of hospital stay in surgical patients [15]. In VLBW infants, only two studies have investigated efficacy of glutamine supplementation $[16,17]$. In the study of Lacey et al [16], 78 VLBW infants at high risk of developing necrotising enterocolitis (birth weight 530-1250 g) were randomised to receive either standard or glutaminesupplemented parenteral nutrition. After exclusion of 34 infants, 22 treated and 22 control infants were compared for length of stay, days on total parenteral nutrition, days on the ventilator and infectious morbidity. In infants with a birth weight $\geq 800 \mathrm{~g}$ no effect of glutamine supplementation was found. However, in infants with a birth weight $<800$ g glutamine supplementation was associated with shorter time to full enteral nutrition, fewer days on parenteral nutrition, fewer days on ventilatory support and reduced length of stay. Incidence of positive blood cultures and rate of weight gain were not different in glutamine and control groups. Neu et al [17] performed a randomised controlled trial of glutamine-enriched enteral nutrition in 68 VLBW infants with a gestational age of 24-
32 weeks and a birth weight of 500-1250 g. Analysis was performed in 66 infants on an intention to treat basis. Feeding tolerance (as measured by number of days on which feeding had to be withheld) was better in the glutamine group compared to the control group. In addition, after adjusting for birth weight the odds ratio of developing sepsis was 3.8 for the control group compared to the glutamine group. Average weight at different time intervals and length of stay were not different between the groups. Although some methodological concerns can be raised (the sample size of both studies is small; Lacey et al [16] did not perform analysis on an intention to treat basis), these studies suggest that glutamine supplementation enhances feeding tolerance and decreases infectious morbidity in VLBW infants.

The current double-blind randomised controlled trial is designed to determine the effect of glutamine-enriched enteral nutrition on feeding tolerance in a sufficient large population VLBW infants. We hypothesise that time to full enteral feeding is shorter in infants who receive glutamine-enriched nutrition compared to infants in the control group. Furthermore, infectious morbidity and short-term outcome are evaluated.

To elucidate the effect of glutamine-enriched enteral nutrition on the functional integrity of the gut, intestinal permeability for macromolecules is measured. As part of the postnatal adaptation of the gut, the intestinal permeability decreases during the first days of life [18]. We hypothesise that glutamine-enriched enteral nutrition stimulates postnatal adaptation of the gut, reflected by a larger decrease in intestinal permeability. Another aspect of postnatal adaptation of the gut is the development of intestinal microflora. In VLBW infants, the colonisation by bacteria (including beneficial Bifidobacterium and Lactobacillus species $[19,20]$ ) commonly present in healthy breast fed infants is delayed [21]. Intestinal mucin is an important site for bacterial adhesion and colonisation [22]. Glutamine may improve mucin quality [4] and consequently influence bacterial colonisation. We hypothesise that glutamine-enriched enteral nutrition stimulates the presence of Bifidobacterium and Lactobacillus species in the intestinal microflora. Intestinal microflora is investigated by determining faecal microflora with a culture independent technique.

The effect of glutamine-enriched enteral nutrition on the immune response is investigated by determining plasma T-helper type 1 (Th1) and T-helper type 2 (Th2) cytokine concentrations following in vitro whole blood stimulation. As pregnancy is associated with skewing towards Th2 immunity [23], Th2 cytokine responses dominate the neonatal immune response [24]. Exposure to microbes stimulates Th1 cytokine responses and deviates the 
neonatal immune response towards balanced Th1/Th2 cytokine responses [24]. We hypothesise that glutamineenriched enteral nutrition contributes to balanced Th1/ Th2 cytokine responses by stimulating the Th1 cytokine response [8].

To assess safety of glutamine-enriched enteral nutrition, plasma amino acid profiles are determined. We hypothesise that plasma amino acid profiles in glutamine and control groups will not differ during the study period. In addition, to exclude negative effects of glutamineenriched enteral nutrition on neurodevelopmental outcome, neuromotor development at the corrected age of 1 and 2 years and mental/motor development at the corrected age of 2 years are assessed.

In conclusion, this double-blind randomised controlled trial aims to determine the effect of glutamine-enriched enteral nutrition on feeding tolerance, infectious morbidity and short-term outcome in VLBW infants. In addition, an attempt is made to elucidate the role of glutamine in postnatal adaptation of the gut and modulation of the immune response.

\section{Methods}

The study is designed as a double-blind randomised clinical trial. The national central committee on research involving human subjects and the medical ethical review board of our hospital approved the study protocol.

\section{Study population}

Infants with a gestational age $<32$ weeks and/or birth weight $<1500 \mathrm{~g}$ admitted to the level III neonatal intensive care unit (NICU) of the VU University Medical Center, Amsterdam, are eligible for participation in the study. Written informed consent is obtained from all parents.

Exclusion criteria are: major congenital or chromosomal anomalies, death $<48 \mathrm{~h}$ after birth, transfer to another hospital $<48 \mathrm{~h}$ after birth and admission from an extraregional hospital.

\section{Treatment allocation and blinding}

To balance birth weight distribution into treatment groups, each infant is stratified to one of three birth weight groups ( $<799 \mathrm{~g}, 800-1199 \mathrm{~g}, \geq 1200 \mathrm{~g})$ and randomly allocated to treatment $<48$ hours after birth. An independent researcher uses a computer-generated randomisation table based on blocks of four (provided by Nutricia Nederland BV, Zoetermeer, The Netherlands) to assign infants to treatment A or B, which correspond to batch numbers on the nutrition products. Investigators, parents, medical and nursing staff are unaware of treatment allocation. The code for the batch numbers is broken after data analysis is performed.

\section{Treatment}

Glutamine powder contains $82 \%$ L-glutamine and $18 \%$ glucose (nitrogen $15.5 \mathrm{wt} / \mathrm{wt} \% ; 371 \mathrm{kcal} / 100 \mathrm{~g}$ ), whereas the isonitrogenous control powder contains $100 \% \mathrm{~L}$ alanine (nitrogen $15.7 \mathrm{wt} / \mathrm{wt} \%, 435 \mathrm{kcal} / 100 \mathrm{~g}$ ). The two powders are indistinguishable by appearance, colour and smell. During the study period, glutamine and control powder are monitored for stability and microbiological contamination.

Between days 3 and 30 of life, supplementation is administered in increasing doses to a maximum of $0.3 \mathrm{~g} / \mathrm{kg}$ glutamine per day in the glutamine group. Initially, the supplementation dose is based on birth weight. After 2 weeks the dose is adjusted to actual weight. Two members of the nursing staff daily add supplementation to breast milk or to preterm formula (Nenatal ${ }^{\circledR}$, Nutricia Nederland B.V., Zoetermeer, The Netherlands), according to the parents' choice. Per $100 \mathrm{ml}$, Nenatal ${ }^{\circledR}$ provides $78 \mathrm{kcal}, 2.1 \mathrm{~g}$ protein (casein-whey protein ratio 40:60), $4.4 \mathrm{~g}$ fat and $7.5 \mathrm{~g}$ carbohydrate. Nenatal ${ }^{\circledR}$ does not contain free Lglutamine. When infants are transferred to other hospitals before the end of the study, the protocol is continued under supervision of the principal investigator.

\section{Nutritional support}

Protocol guidelines for the introduction of parenteral and enteral nutrition follow current practice at our NICU. Administration of parenteral nutrition starts at day 2 and will be advanced gradually until amino-acid intake reaches $3 \mathrm{~g} / \mathrm{kg} /$ day at day 6 . Parenteral nutrition is discontinued if enteral feeding reaches a volume of approximately $150 \mathrm{~mL} / \mathrm{kg} /$ day. Parenteral nutrition, an all-in-one mixture provided by the hospital pharmacy, contains per $100 \mathrm{~mL} 54 \mathrm{kcal}, 8.5 \mathrm{~g}$ glucose, $1.7 \mathrm{~g}$ amino acids and 1.7 g lipids. If necessary, glucose, amino acids and lipids are given in separate solutions.

Guidelines for the introduction of enteral nutrition are as follows: 1. minimal enteral nutrition starts at day 1 (6-12 $\mathrm{mL}$ daily); 2 . enteral nutrition is advanced either from day 3 or from day 5 in case of complications: BW $<$ p10, GA $<26$ weeks, Apgar score at 5 minutes $<6$, umbilical artery $\mathrm{pH}<7.10$ or base deficit $>10 \mathrm{mmol} / \mathrm{L} ; 3$. feeding is advanced at a dose of $15-20 \mathrm{~mL} / \mathrm{kg} /$ day to a maximum of $150 \mathrm{~mL} / \mathrm{kg} /$ day (based on actual weight). Furthermore, guidelines for reduction/withholding of enteral feeding are: 1 . enteral feeding is reduced/withheld in case of gastric residuals ( $>$ total volume of past 2 feedings), bilious residuals, emesis, ileus or necrotising enterocolitis Bell's stage $\geq$ II [25]; 2 . when signs of feeding intolerance resolve, feeding is advanced in the volume given before reduction/withholding within 2 days. 
Table I: Clinical outcome measures

\begin{tabular}{|c|c|}
\hline & Remarks \\
\hline \multicolumn{2}{|l|}{ Feeding tolerance } \\
\hline Enteral feeding $>120 \mathrm{~mL} / \mathrm{kg} /$ day & Primary outcome \\
\hline \multicolumn{2}{|l|}{ Age at finishing parenteral nutrition } \\
\hline \multicolumn{2}{|l|}{ Days of no enteral feeding during study period } \\
\hline Necrotising enterocolitis & Bell et al [25] \\
\hline \multicolumn{2}{|l|}{ Infectious morbidity } \\
\hline \multicolumn{2}{|l|}{ Serious infections } \\
\hline \multicolumn{2}{|l|}{ Number of infectious episodes } \\
\hline \multicolumn{2}{|l|}{ Cultured micro-organisms } \\
\hline \multicolumn{2}{|l|}{ Short-term outcome } \\
\hline Weight $z$ scores at birth, day 30 and at discharge & Usher et al [33] \\
\hline \multicolumn{2}{|l|}{ Patent ductus arteriosus } \\
\hline \multicolumn{2}{|l|}{ Ventilatory support } \\
\hline Use of oxygen at postmenstrual age of 36 weeks & Jobe et al [34] \\
\hline Intraventricular hemorrhage & Papile et al [35] \\
\hline Retinopathy of prematurity & Committee for ROP [36] \\
\hline \multicolumn{2}{|l|}{ Death } \\
\hline Age at discharge from NICU and at discharge hom & \\
\hline
\end{tabular}

ROP = retinopathy of prematurity; NICU = neonatal intensive care unit.

For each infant in the study a feeding schedule is proposed, based on birth weight and the guidelines as mentioned above. However, the staff of our NICU has final responsibility for the administration of parenteral nutrition and advancement of enteral feeding.

\section{Study outcome measures}

\section{Study outcome measures}

Primary outcome of the study is time to full enteral feeding, defined as a feeding volume $\geq 120 \mathrm{~mL} / \mathrm{kg} /$ day. Furthermore, other parameters of feeding tolerance, infectious morbidity, and short-term outcome are evaluated (Table 1). In addition to clinical outcome, intestinal permeability, faecal flora, plasma Th1/Th2 cytokine concentrations and plasma amino acid profiles are determined during the 30 day study period (Table 2).

\section{Clinical outcome measures}

The following perinatal characteristics are registered to assess prognostic similarity: maternal age and race, obstetric diagnosis, administration of antenatal steroids and antibiotics, mode of delivery, sex, gestational age, birth weight, birth weight $<$ p10, Apgar scores, pH of the umbilical artery, clinical risk index for babies [26] and administration of surfactant.

During the study period actual intake of enteral and parenteral nutrition, powder supplementation and type of feeding (breast milk or preterm formula) are recorded daily.
Evaluation of medical records for the presence of serious infections is performed by one investigator/neonatologist, unaware of treatment allocation. Serious infections include sepsis, meningitis, pyelonephritis, pneumonia, and arthritis. Sepsis work-up consists of blood, cerebrospinal fluid and urine (suprapubic bladder tap) culture. Sepsis is defined as the combination of a positive blood culture and the presence of at least two clinical signs (body temperature $<36.5^{\circ} \mathrm{C}$ or $>37.5^{\circ} \mathrm{C}$, hypotension, tachycardia, apnoeic attacks, feeding problems, irritability or apathy). Meningitis is diagnosed when microorganisms are cultured in the cerebrospinal fluid. Pyelonephritis is diagnosed when both urine culture and dimercaptosuccinic acid (DMSA) renal scan are positive. Pneumonia is defined as the combination of a positive culture of tracheal aspirate, bronchial secretion or sputum and the presence of at least one clinical sign in ventilated infants (purulent sputum, changed sputum characteristics or deterioration of ventilation settings) or at least two clinical signs in non-ventilated infants (tachypnea, cyanosis, wheezing/rales/crepitation or purulent sputum/ changed sputum characteristics). Arthritis is defined as the combination of a positive culture of intra-articular fluid and the presence of signs of articular inflammation.

Postnatal adaptation of the gut

The effect of glutamine-enriched enteral nutrition on postnatal adaptation of the gut is studied by measuring intestinal permeability and by determining faecal flora. 
Table 2: Study schedule

\begin{tabular}{|c|c|c|c|c|}
\hline & $<48 \mathrm{~h}$ & day 7 & day 14 & day 30 \\
\hline Amino acid profile & $x$ & $x$ & $x$ & $x$ \\
\hline Intestinal permeability & $x$ & $x$ & $x$ & $x$ \\
\hline Faecal flora & $x$ & $x$ & $x$ & $x$ \\
\hline ThI/Th2 cytokine profile & $x$ & $x$ & $x$ & - \\
\hline
\end{tabular}

Intestinal permeability is measured by the sugar absorption test, as previously described [18]. After instillation of the test solution, $2 \mathrm{ml} / \mathrm{kg}$ by nasogastric tube, urine is collected for 6 hours. After collection, $0.5 \mathrm{ml}$ chlorohexidine digluconate $20 \%$ (preservative) is added to the urine and samples are stored at $-20^{\circ} \mathrm{C}$ until analysis. Lactulose and mannitol concentrations ( $\mathrm{mmol} / \mathrm{mol}$ creatinine) are measured by gas chromatography as previously described [27]. The lactulose/mannitol ratio is used as a measure of intestinal permeability.

Faecal samples are stored at $-20^{\circ} \mathrm{C}$ until analysis by fluorescent in situ hybridisation (FISH) using specific 16S rDNA-targeted probes as described by Harmsen et al [28].

\section{Immune response}

The effect of glutamine enriched-enteral nutrition on the immune response is investigated by determining plasma Th1/Th2 cytokine concentrations following in vitro whole blood stimulation. Heparinized blood $(0.5 \mathrm{~mL})$, diluted 1:1 in sterile medium (RPMI 1640 without L-glutamine, Gibco, Paisley, United Kingdom) is stimulated for $24 \mathrm{~h}$ at $37^{\circ} \mathrm{C}$ in the presence of anti-CD3/anti-CD28 (Central Laboratory of the Netherlands Red Cross Blood Transfusion service, Amsterdam, the Netherlands) and Escherichia coli lipopolysaccharide (concentration 1:1000 both). After incubation, blood is centrifugated, supernatant is collected and stored at $-20^{\circ} \mathrm{C}$ until analysis. Th1 cytokines IFN- $\gamma$, TNF- $\alpha$, IL- 2 and Th 2 cytokines IL-4, IL- 5 and IL-10 are measured by cytometric bead array (BD biosciences, Alphen aan den Rijn, the Netherlands).

\section{Safety}

Safety of enteral glutamine supplementation in a dosage of $0.3 \mathrm{~g} / \mathrm{kg} /$ day is investigated by determination of plasma amino acid profiles. Immediately after withdrawal, heparinized blood $(0.5 \mathrm{~mL})$ is centrifuged at $10000 \mathrm{rpm}$ for 4 minutes. Plasma is deproteinized by sulfosalicylic acid $(2 \mathrm{mg} / 100 \mu \mathrm{L})$ and stored at $-70^{\circ} \mathrm{C}$ until analysis. Amino acid profiles are determined by high-performance liquid chromatography as described by Teerlink et al [29].

To investigate neurodevelopmental outcome, neuromotor development at the corrected age of 1 and 2 years [30] and mental/motor development at the corrected age of 2 years are assessed [31].

\section{Sample size}

We have calculated that a sample size of 102 infants is necessary to detect a difference of at least 2.5 days in time to full enteral feeding, assuming a SD of 4.5 days (twotailed $\alpha=0.05, \beta=0.20$ ). The SD value is based on an retrospective analysis of time to full enteral feeding in infants with GA $<32$ weeks and/or BW $<1500$ g admitted to our NICU in 1998.

\section{Statistical analysis}

To determine whether randomisation is successful, prognostic similarity (perinatal and nutritional characteristics) between treatment groups is assessed. The Students' t-test, Mann-Whitney U test, and chi-square test or Fisher's exact test are used to compare continuous normally distributed data, nonparametric continuous data and dichotomous data respectively.

Cox regression is performed to examine the effect of glutamine-enriched enteral nutrition on time to full enteral feeding. Logistic regression is performed to examine whether glutamine-enriched enteral nutrition influences the incidence of serious infections. In an additional analysis, adjustments are made for possible confounding factors as administration of antenatal corticosteroids, birth weight $<$ p10, administration of breast milk and other prognostic factors that may be different between treatment groups.

Analyses of secondary outcomes (only crude) is performed by Mann-Whitney U test, chi-square test or Fisher's exact test and log rank test for nonparametric continuous data, dichotomous data, and time-dependent data respectively.

Generalised estimated equations for longitudinal analysis [32] are used to analyse changes over time in intestinal permeability, faecal microflora, plasma Th1/Th2 cytokine concentrations and plasma amino acid profiles. 
Distribution of optimal and non-optimal neuromotor development and normal and abnormal mental/motor development in glutamine and control groups is examined by logistic regression with adjustments for possible confounding factors as gestational age and birth weight.

All statistical analyses are performed on an intention to treat basis. In addition, alternative per protocol analyses are performed, excluding all patients who are not treated according to protocol, defined as more than 3 consecutive days or a total of 5 days on minimal enteral feeding or without supplementation.

A p value $<0.05$ is considered significant (two-tailed). SPSS 9.0 (SPSS Inc., Chicago, IL, USA) and STAT 7.0 (StatCorp LP, College Station, TX, USA) are used for data analysis.

\section{Competing interests}

Nutricia Nederland B.V. (Zoetermeer, the Netherlands) provided $\mathrm{Nenatal}^{\circledR}$, glutamine and placebo supplementation.

\section{Authors' contributions}

Ruurd van Elburg and Willem Fetter formulated the research question and wrote the study protocol. Anemone van den Berg, Ruurd van Elburg and Willem Fetter contributed to the development of the protocol. Jos Twisk gave advice on data analysis. Anemone van den Berg wrote the draft for this manuscript and the other authors reviewed the manuscript. All authors approved the final version of the manuscript.

\section{Acknowledgements}

We would like to thank HN Lafeber, AM van Furth and J Knol for their contribution to the study design.

\section{References}

I. Peeters LL, Sheldon RE, Jones MD Jr, Makowski EL, Meschia G: Blood flow to fetal organs as a function of arterial oxygen content. Am J Obstet Gynecol 1 979, 135:637-646.

2. Windmueller HG, Spaeth $A E$ : Respiratory fuels and nitrogen metabolism in vivo in small intestine of fed rats. Quantitative importance of glutamine, glutamate, and aspartate. J Biol Chem 1980, 255:107-II2.

3. Panigrahi $\mathrm{P}, \mathrm{Gewolb} \mathrm{IH}$, Bamford $\mathrm{P}$, Horvath K: Role of glutamine in bacterial transcytosis and epithelial cell injury. JPEN J Parenter Enteral Nutr 1997, 21:75-80.

4. Khan J, liboshi Y, Cui L, Wasa M, Sando K, Takagi Y, et al.: Alanylglutamine-supplemented parenteral nutrition increases luminal mucus gel and decreases permeability in the rat small intestine. JPEN J Parenter Enteral Nutr 1999, 23:24-3I.

5. Rhoads JM, Argenzio RA, Chen W, Rippe RA, Westwick JK, Cox AD, et al.: L-glutamine stimulates intestinal cell proliferation and activates mitogen-activated protein kinases. Am J Physiol 1997, 272:G943-G953.

6. Parry-Billings M, Evans J, Calder PC, Newsholme EA: Does glutamine contribute to immunosuppression after major burns? Lancet 1990, 336:523-525.

7. Spittler A, Winkler S, Gotzinger P, Oehler R, Willheim M, Tempfer C, et al.: Influence of glutamine on the phenotype and function of human monocytes. Blood 1995, 86:1564-1569.
8. Chang WK, Yang KD, Shaio MF: Effect of glutamine on ThI and Th2 cytokine responses of human peripheral blood mononuclear cells. Clin Immunol I 999, 93:294-30I.

9. Lacey JM, Wilmore DW: Is glutamine a conditionally essential amino acid? Nutr Rev 1990, 48:297-309.

10. O'Dwyer ST, Smith RJ, Hwang TL, Wilmore DW: Maintenance of small bowel mucosa with glutamine-enriched parenteral nutrition. JPEN J Parenter Enteral Nutr 1989, 13:579-585.

II. Kafkewitz D, Bendich A: Enzyme-induced asparagine and glutamine depletion and immune system function. Am J Clin Nutr 1983, 37: 1025-1030.

12. Griffiths RD, Jones C, Palmer TE: Six-month outcome of critically ill patients given glutamine-supplemented parenteral nutrition. Nutrition 1997, 13:295-302.

13. Ziegler TR, Young LS, Benfell K, Scheltinga M, Hortos K, Bye R, et al:: Clinical and metabolic efficacy of glutamine-supplemented parenteral nutrition after bone marrow transplantation. A randomized, double-blind, controlled study. Ann Intern Med 1992, I | 6:821-828.

14. Houdijk AP, Rijnsburger ER, Jansen J, Wesdorp RI, Weiss JK, McCamish MA, et al.: Randomised trial of glutamine-enriched enteral nutrition on infectious morbidity in patients with multiple trauma. Lancet 1998, 352:772-776.

15. Morlion BJ, Stehle P, Wachtler P, Siedhoff HP, Koller M, Konig W, et al.: Total parenteral nutrition with glutamine dipeptide after major abdominal surgery: a randomized, double-blind, controlled study. Ann Surg 1998, 227:302-308.

16. Lacey JM, Crouch JB, Benfell K, Ringer SA, Wilmore CK, Maguire D, et al:: The effects of glutamine-supplemented parenteral nutrition in premature infants. JPEN J Parenter Enteral Nutr 1996, 20:74-80.

17. Neu J, Roig JC, Meetze WH, Veerman M, Carter C, Millsaps M, et al:: Enteral glutamine supplementation for very low birth weight infants decreases morbidity. J Pediatr 1997, I 3 I:691 I-699.

18. van Elburg RM, Fetter WP, Bunkers CM, Heymans HS: Intestinal permeability in relation to birth weight and gestational and postnatal age. Arch Dis Child Fetal Neonatal Ed 2003, 88:F52-F55.

19. Sakata H, Yoshioka H, Fujita K: Development of the intestinal flora in very low birth weight infants compared to normal full-term newborns. Eur J Pediatr 1985, I 44:186-190.

20. Hall MA, Cole CB, Smith SL, Fuller R, Rolles CJ: Factors influencing the presence of faecal lactobacilli in early infancy. Arch Dis Child 1990, 65:185-188.

21. Orrhage K, Nord CE: Factors controlling the bacterial colonization of the intestine in breastfed infants. Acta Paediatr Suppl 1999, 88:47-57.

22. Mikelsaar M, Mänder R, Sepp E: Lactic acid microflora in the human microbial ecosystem and its development. In Lactic Acid Bacteria: Microbiology and Functional Aspects Edited by: Salminen S, von Wright A. New York: Marcel Dekker; 1998:279-342.

23. Wegmann TG, Lin H, Guilbert L, Mosmann TR: Bidirectional cytokine interactions in the maternal-fetal relationship: is successful pregnancy a TH2 phenomenon? Immunol Today 1993, 14:353-356

24. Holt PG, Sly PD, Bjorksten B: Atopic versus infectious diseases in childhood: a question of balance? Pediatr Allergy Immunol I997, 8:53-58.

25. Bell MJ, Ternberg JL, Feigin RD, Keating JP, Marshall R, Barton L, et al.: Neonatal necrotizing enterocolitis. Therapeutic decisions based upon clinical staging. Ann Surg 1978, 187:1-7.

26. The CRIB (clinical risk index for babies) score: a tool for assessing initial neonatal risk and comparing performance of neonatal intensive care units. The International Neonatal Network. Lancet 1993, 342:193-198.

27. van Elburg RM, Uil JJ, Kokke FT, Mulder AM, van de Broek WG, Mulder CJ, et al.: Repeatability of the sugar-absorption test, using lactulose and mannitol, for measuring intestinal permeability for sugars. J Pediatr Gastroenterol Nutr 1995, 20:184-188.

28. Harmsen HJ, Wildeboer-Veloo AC, Raangs GC, Wagendorp AA, Klijn N, Bindels JG, et al.: Analysis of intestinal flora development in breast-fed and formula-fed infants by using molecular identification and detection methods. J Pediatr Gastroenterol Nutr 2000, 30:61-67.

29. Teerlink T, van Leeuwen PA, Houdijk A: Plasma amino acids determined by liquid chromatography within 17 minutes. Clin Chem 1994, 40:245-249. 
30. Samsom JF, de Groot L: The influence of postural control on motility and hand function in a group of 'high risk' preterm infants at I year of age. Early Hum Dev 2000, 60: I0I-II3.

3I. Bayley N: Bayley Scales of Infant development II. 2nd edition. New York, The Psychological Corporation; 1993.

32. Twisk JWR: Applied longitudinal data analysis for epidemiology. A practical guide Cambridge UK: Cambridge University Press; 2003.

33. Usher R, McLean F: Intrauterine growth of live-born Caucasian infants at sea level: standards obtained from measurements in 7 dimensions of infants born between 25 and 44 weeks of gestation. J Pediatr 1969, 74:901-910.

34. Jobe $\mathrm{AH}$, Bancalari E: Bronchopulmonary dysplasia. Am J Respir Crit Care Med 200I, 163:1723-1729.

35. Papile LA, Burstein J, Burstein R, Koffler H: Incidence and evolution of subependymal and intraventricular hemorrhage: a study of infants with birth weights less than $1,500 \mathrm{gm}$. J Pediatr 1978, 92:529-534.

36. An international classification of retinopathy of prematurity. The Committee for the Classification of Retinopathy of Prematurity. Arch Ophthalmol 1984, 102: I 130-1 I34.

\section{Pre-publication history}

The pre-publication history for this paper can be accessed here:

http://www.biomedcentral.com/1471-2431/4/17/prepub

Publish with Biomed Central and every scientist can read your work free of charge

"BioMed Central will be the most significant development for disseminating the results of biomedical research in our lifetime. "

Sir Paul Nurse, Cancer Research UK

Your research papers will be:

- available free of charge to the entire biomedical community

- peer reviewed and published immediately upon acceptance

- cited in PubMed and archived on PubMed Central

- yours - you keep the copyright

Submit your manuscript here:

http://www.biomedcentral.com/info/publishing_adv.asp 